\title{
Numerical Simulation of the Rock SHPB Test with a Special Shape Striker Based on the Discrete Element Method
}

\author{
Xibing Li $\cdot$ Yang Zou $\cdot$ Zilong Zhou
}

Received: 25 March 2013/Accepted: 19 September 2013/Published online: 8 October 2013

(C) Springer-Verlag Wien 2013

\begin{abstract}
A split Hopkinson pressure bar (SHPB) system with a special shape striker has been suggested as the test method by the International Society for Rock Mechanics (ISRM) to determine the dynamic characteristics of rock materials. In order to further verify this testing technique and microscopically reveal the dynamic responses of specimens in SHPB tests, a numerical SHPB test system was established based on particle flow code (PFC). Numerical dynamic tests under different impact velocities were conducted. Investigation of the stresses at the ends of a specimen showed that the specimen could reach stress equilibrium after several wave reverberations, and this balance could be maintained well for a certain time period after the peak stress. In addition, analyses of the reflected waves showed that there was a clear relationship between the variation of the reflected wave and the stress equilibrium state in the specimen, and the turning point of the reflected wave corresponded well with the peak stress in the specimen. Furthermore, the reflected waves can be classified into three types according to their patterns. Under certain impact velocities, the specimen deforms at a constant strain rate during the whole loading process. Finally, the influence of the micro-strength ratio $\left(\tau_{\mathrm{c}} / \sigma_{\mathrm{c}}\right)$ and distribution pattern on the dynamic increase factor (DIF) of the strength DIF were studied, and the lateral inertia
\end{abstract}

X. Li · Y. Zou $(\bowtie) \cdot$ Z. Zhou

School of Resources and Safety Engineering, Central South

University, Changsha 410083,

Hunan, People's Republic of China

e-mail: zouyang_csu@163.com

\section{Y. Zou}

School of Architecture, Civil and Environmental Engineering, Laboratory for Rock Mechanics (LMR), École Polytechnique Fédérale de Lausanne (EPFL), 1015 Lausanne, Switzerland confinement and heterogeneity were found to be two important factors causing the strain rate effect for rock materials.

Keywords SHPB - Special shape striker - Discrete element method . Strain rate effect

\section{List of Symbols}

DEM Discrete element method

DIF Dynamic increase factor

ISRM International Society for Rock Mechanics

PFC Particle flow code

SHPB Split Hopkinson pressure bar

$\varepsilon_{\mathrm{I}} \quad$ Incident strain signal on the incident bar

$\varepsilon_{\mathrm{R}} \quad$ Reflected strain signal on the incident bar

$\varepsilon_{\mathrm{T}} \quad$ Transmitted strain signal on the transmitted bar

$\sigma_{\mathrm{I}} \quad$ Incident stress signal on the incident bar

$\sigma_{\mathrm{R}} \quad$ Reflected stress signal on the incident bar

$\sigma_{\mathrm{T}} \quad$ Transmitted stress signal on the transmitted bar

$\sigma \quad$ Stress of the specimen

$\varepsilon \quad$ Strain of the specimen

$\dot{\varepsilon} \quad$ Strain rate of the specimen $\left(\mathrm{s}^{-1}\right)$

$A_{\mathrm{b}} \quad$ Cross-sectional area of the elastic bars $\left(\mathrm{m}^{2}\right)$

$C_{\mathrm{b}} \quad$ Wave velocity of the elastic bars $(\mathrm{m} / \mathrm{s})$

$E_{\mathrm{b}} \quad$ Young's modulus of the elastic bars (MPa)

$A_{\mathrm{s}} \quad$ Cross-sectional area of the specimen $\left(\mathrm{m}^{2}\right)$

$L_{\mathrm{s}} \quad$ Length of the specimen (m)

$L_{\mathrm{I}} \quad$ Length of the incident bar $(\mathrm{m})$

$L_{\mathrm{T}} \quad$ Length of the transmitted bar (m)

$F_{I j} \quad$ Axial contact force of particle $j$ at the specimen's incident end $(\mathrm{N})$

$F_{T i} \quad$ Axial contact force of particleiat the specimen's transmitted end $(\mathrm{N})$

$N_{\mathrm{I}} \quad$ Total number of the specimen's particles contacting with the incident bar 
$N_{\mathrm{T}} \quad$ Total number of the specimen's particles contacting with the transmitted bar

$\sigma_{\mathrm{SI}} \quad$ Stress at the specimen's incident end (MPa)

$\sigma_{\mathrm{ST}} \quad$ Stress at the specimen's transmitted end (MPa)

$r \quad$ Radius of the specimen (m)

$\delta \quad$ Thickness of the particles (m)

$\eta \quad$ Stress equilibrium factor

$\dot{\varepsilon}_{\mathrm{R}} \quad$ Strain rate of the specimen calculated from the reflected waves $\left(\mathrm{s}^{-1}\right)$

$\dot{\varepsilon}_{\mathrm{s}} \quad$ Strain rate of the specimen obtained through the measuring circles $\left(\mathrm{s}^{-1}\right)$

$t_{\mathrm{i}} \quad$ Moment when the loading wave first arrives at the specimen's incident end (s)

$t_{\mathrm{t}} \quad$ Moment when the loading wave first arrives at the specimen's transmitted end (s)

$t_{\mathrm{b}} \quad$ Moment when stress equilibrium is first achieved at the specimen's two ends (s)

$t_{\mathrm{p}} \quad$ Moment when the stress in the specimen reaches its peak value

$t_{\mathrm{d}} \quad$ Moment when the specimen is damaged

$t_{\mathrm{e}} \quad$ Moment when the loading process ends

$\lambda$ Reflection coefficient at the specimen/bar interface

$\tau_{\mathrm{c}} \quad$ Contact-bond shear strength (MPa)

$\sigma_{\mathrm{c}} \quad$ Contact-bond normal strength (MPa)

$\tau_{\mathrm{c}} / \sigma_{\mathrm{c}} \quad$ Micro-strength ratio (ratio of contact-bond shear to normal strength)

$n \quad$ Time-step

$N \quad$ Current time-step

$\Delta T(n) \quad$ Interval time under time-step $n(\mathrm{~s})$

$\mu \quad$ Frictional coefficient at the specimen/bar interface

\section{Introduction}

The split Hopkinson pressure bar (SHPB) system, developed by Kolsky, was first used to investigate the dynamic behaviors of metal materials (Kolsky 1949). Then, it was gradually imported into the studies of brittle materials like rock, ceramic, and concrete (Kumar 1968; Ravichandran and Subhash 1994; Li and Gu 1994; Al-Mousawi et al. 1997; Tedesco and Ross 1998; Zhao et al. 1999; Cai et al. 2007; Demirdag et al. 2010; Zhang and Zhao 2013a). However, because of the brittle and heterogeneous characteristics of rock-like materials, the technique was plagued with the following problems: (1) difficulty in achieving stress uniformity and equilibrium in the specimen; (2) premature failure of the specimen before stress equilibrium; (3) high oscillation of the incident wave; and (4) difficulty in ensuring the specimen's deformation at a constant strain rate (Lok et al. 2002; Frew et al. 2001; Li et al. 2000). To overcome these shortcomings, a loading method which can generate a half-sine incident wave by a special striker has been proposed and proved to be reliable to some extent (Li et al. 2000, 2005, 2008, 2011; Zhang and Zhao $2013 \mathrm{~b}, \mathrm{c})$. It has been suggested as one of the test methods by the International Society for Rock Mechanics (ISRM) to determine the dynamic characteristics of rock materials (Zhou et al. 2012). Although the method has been proved to be efficient and reliable in the laboratory, some important micro-mechanisms like wave propagation, stress interference, the failure process of the specimen, and the strain rate effect, which are vital to explaining the system performance and specimen behaviors, are still unclear, with the restrictions of current testing techniques.

Numerical simulation, on the other hand, can reveal the stress and deformation details at micro-levels more easily. To date, a limited number of simulations on SHPB tests have been mainly about conventional SHPB with a cylindrical striker, and the simulation codes are usually finite element methods (Bertholf and Karnes 1975; Park et al. 2001; Li and Meng 2003; Cotsovos and Pavlović 2008; Lu et al. 2010; Zhu et al. 2012). There are several drawbacks to these simulation works: (1) the presumed material constitutive relations should be given in advance, which causes the simulation to run as expected. These simulation results have limitations in reflecting the essential mechanical properties of materials. (2) The numerical models of the SHPB system were usually simplified. In some cases, the specified loading is applied on the specimen directly. In other cases, the impact loading is usually not based on the simulation of the actual impact between the rod and the striker, but simplified to apply an ideal wave to the rod's end directly, which is different from the reality. (3) It is difficult to simulate the crack propagation or crushing damage of the sample efficiently, even though this is crucial to the research on rock dynamic failure.

Compared with the finite element method, which is based on continuum mechanics, the discrete element method (DEM) is able to overcome the above problems appropriately. Firstly, there is no need to make an assumption on the material constitution. For its micro-mechanical foundation, it offers a useful simulation tool for understanding the dynamic mechanisms of rock materials at the micro-scale directly (Potyondy and Cundall 2004). Secondly, real-time searching for contacts makes it convenient to simulate the actual impact process. In addition, in DEM, cracks form, interact, and coalesce into macroscopic fractures as a consequence of bond breakage between particles. This ensures that the numerical model can simulate the dynamic crushing failure of rock effectively (Hazzard et al. 2000; Qi et al. 2009).

In this paper, a numerical model was first established to simulate the SHPB system with a special shape striker suggested by the ISRM based on the DEM. Then, numerical dynamic tests were carried out to analyze the stress equilibrium and the strain rate evolution of specimens, which provided the means to check the validity of tests and 
gain a deeper understanding of the damage propagation in the specimen. Finally, several dynamic experiments were conducted to investigate the micro-mechanism of the strain rate effect of rock materials.

\section{SHPB Technique}

The SHPB test system consists of an incident bar and a transmitted bar, with a specimen sandwiched between them, and a special shape striker (the dimensions of which are shown in Fig. 1b) impacts the incident bar to produce a compressive stress wave, as shown in Fig. 1a. The diameter, elastic modulus, and density of the elastic bars are $50 \mathrm{~mm}$, $240 \mathrm{GPa}$, and 7,800 kg/m $\mathrm{m}^{3}$, respectively (Zhou et al. 2011).

If we use ato denote the measured strain signal on the bars, where the subscripts I, R, and $\mathrm{T}$ represent incident, reflected, and transmitted pulses, respectively, according to the one-dimensional stress wave theory, the stress, strain, and strain rate of the sample can be expressed as:

$\sigma=\frac{A_{\mathrm{b}}}{2 A_{\mathrm{s}}} E_{\mathrm{b}}\left[\varepsilon_{\mathrm{I}}(t)+\varepsilon_{\mathrm{R}}(t)+\varepsilon_{\mathrm{T}}(t)\right]$

$\varepsilon=\frac{C_{\mathrm{b}}}{L_{\mathrm{s}}} \int_{0}^{t}\left[\varepsilon_{\mathrm{I}}(t)-\varepsilon_{\mathrm{R}}(t)-\varepsilon_{\mathrm{T}}(t)\right] \mathrm{d} t$

$\dot{\varepsilon}=\frac{C_{\mathrm{b}}}{L_{\mathrm{S}}}\left[\varepsilon_{\mathrm{I}}(t)-\varepsilon_{\mathrm{R}}(t)-\varepsilon_{\mathrm{T}}(t)\right]$

where $A_{\mathrm{b}}, C_{\mathrm{b}}$, and $E_{\mathrm{b}}$ are the cross-sectional area, wave velocity, and Young's modulus of elastic bars, respectively. $A_{\mathrm{s}}$ and $L_{\mathrm{s}}$ are the cross-sectional area and length of the specimen, respectively. $\dot{\varepsilon}$ is the strain rate of the specimen.

\section{PFC Model of the SHPB System with a Special Shape Striker}

Models in two-dimensional (2D) particle flow code (PFC) are composed of discrete circular particle aggregates (or containing walls), in which the particles are regarded as rigid and contacts are allowed within a very small area between particles (Cundall and Strack 1979). The particles' movements obey the Newtonian second law and the contact force is calculated according to the inherent relationship between force and displacement, which is determined by the contact models in PFC. Among these, the linear springs and contact bond which are often used to simulate the mechanical behavior of brittle rock materials in other literature (Read 2004; Deluzarche and Cambou 2006; Wang and Tonon 2009; Diederichs et al. 2004) are selected. In addition, because PFC uses an explicit approach to solve the equations of motion, it can be conveniently used in dynamic simulations (Hentz et al. 2004; Hazzard and Young 2004).

After comprehensive consideration of the accuracy and quantity of the numerical calculation, the radius range of particles is selected to be $0.9-3.0 \mathrm{~mm}$. The density of particles is $7,894.7 \mathrm{~kg} / \mathrm{m}^{3}$, deduced from the mass conservation law. The microscopic deformation parameters of particles including the normal and shear stiffness are $6.86 \times 10^{11}$ and $2.45 \times 10^{11} \mathrm{~N} / \mathrm{m}$, respectively, which are calibrated through a static numerical compressive test based on the realistic physical parameters of SHPB bars. As the bars should hardly be damaged during the whole impact test, the contact bond strength is assumed to be large enough $\left(1 \times 10^{100} \mathrm{MPa}\right)$.

Under the above micro-parameters, the numerical SHPB system with a special shape striker (Fig. 1c) suggested by

(a)

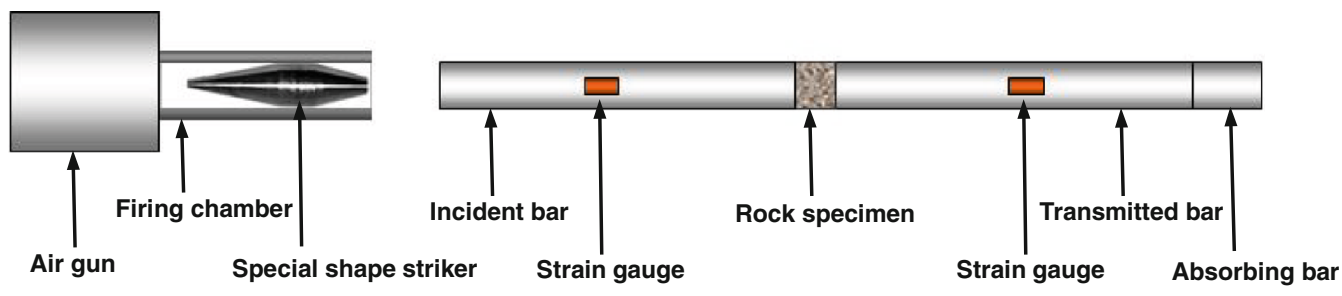

(b)

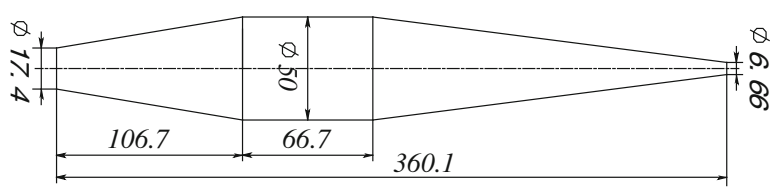

(c)

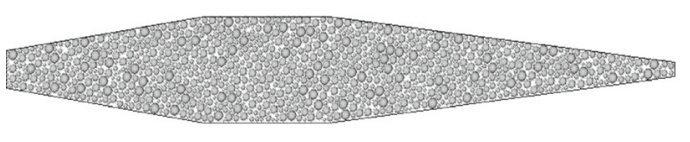

Fig. 1 SHPB test system with a special shape striker: a SHPB equipment; $\mathbf{b}$ dimensions of the special shape striker; $\mathbf{c}$ particle model of the special shape striker 
the ISRM is established. Figure 2a1 shows the model of the testing system, in which the lengths of the SHPB bars should satisfy certain restrictions to ensure the validity of the test: (1) the length of the incident bar should ensure that the bending wave produced from the impact end will not propagate into the specimen within the time it takes for the wave to reflect back and forth 9-10 times in the specimen; (2) the length of the incident and transmitted bars should also ensure that the initial reflected and transmitted wave cannot disturb the specimen's stress equilibrium after they reflect on the end of the corresponding bars within this time ( $\mathrm{Li}$ and $\mathrm{Gu}$ 1994). According to these rules and the principle of decreasing the amount of calculation to be as small as possible, the lengths of incident bar $L_{\mathrm{I}}$ and transmitted bar $L_{\mathrm{T}}$ are selected to be 1.5 and $0.75 \mathrm{~m}$, respectively. The diameter of the bars is $50 \mathrm{~mm}$, which is the same as that in reality. In order to monitor the wave propagation along the bars, measuring circles were assigned at points $\mathrm{A}, \mathrm{B}, \mathrm{C}, \mathrm{D}$, and $\mathrm{E}$.

(a)

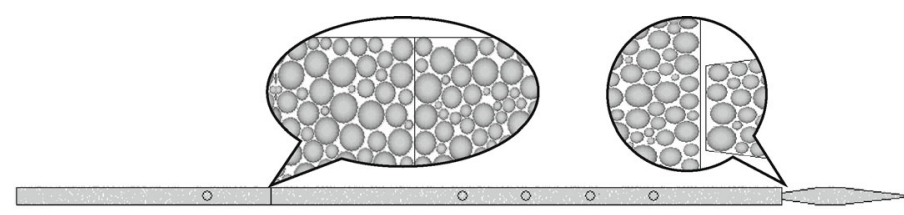

(a1) Contact particles without alignment

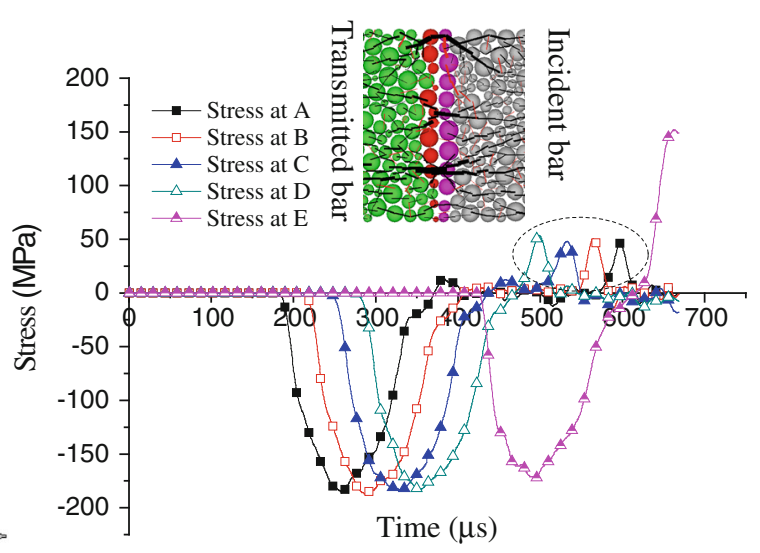

(a2) Stress waves in the bars

(b)

To simulate the actual impact process, the striker generated by the particles is given an applicable velocity in the direction of the incident bar. The waves generated under an impact velocity of $10 \mathrm{~m} / \mathrm{s}$ are shown in Fig. 2a). It is quite similar to the experimental waveform without an apparent dispersion phenomenon ( $\mathrm{Li}$ et al. 2005; Zhou et al. 2010). But from the protrusions of the incident signals and the obvious decrease in the amplitude of the transmitted wave compared with the incident wave, it can be inferred that there is a tensile wave propagating in a reverse direction and the incident wave does not transmit into the transmitted bar completely. From the local detailed view of the contact interface between the bars (the black line denotes compressive contact force and the red line represents tensile contact force), it can further be seen that the contact force at the interface is not uniform. In order to improve the contact condition, the particles on the two sides at the contact interface were aligned and had the same diameter, as shown in Fig. $2 b 1$. (b1) Contact particles with careful alignment

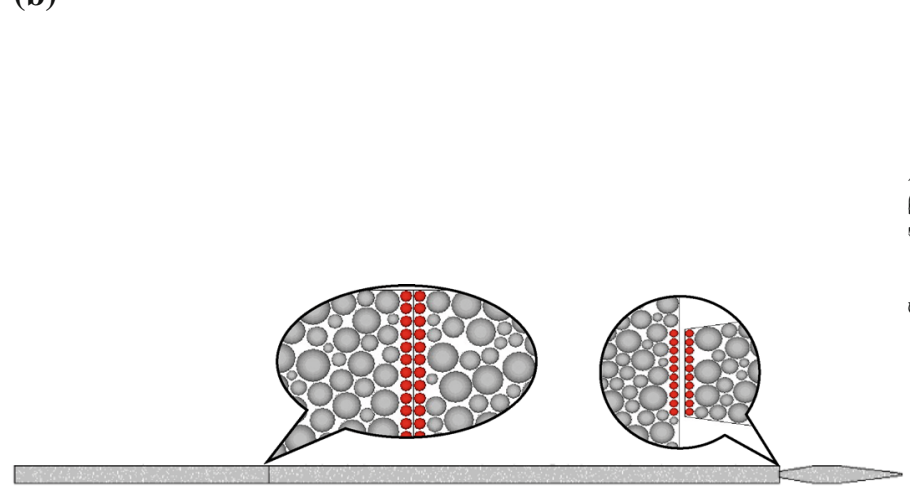

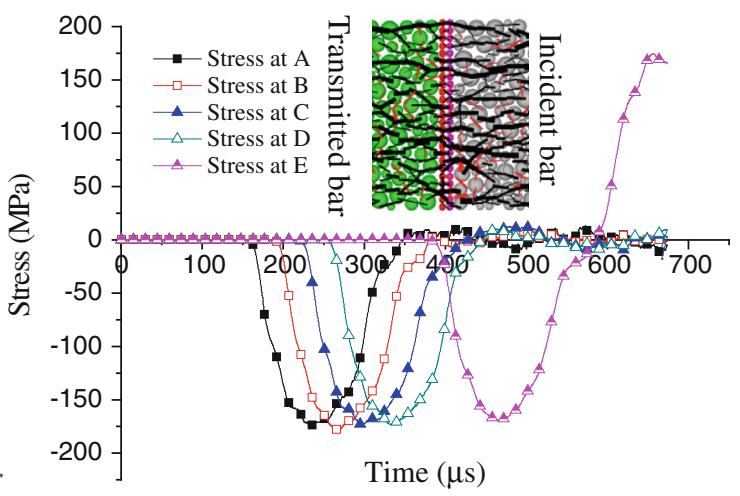

(b2) Stress waves in the bars

Fig. 2 Numerical SHPB test system with a special shape striker: a numerical SHPB test system without improved scheme; b numerical SHPB test system with improved scheme 

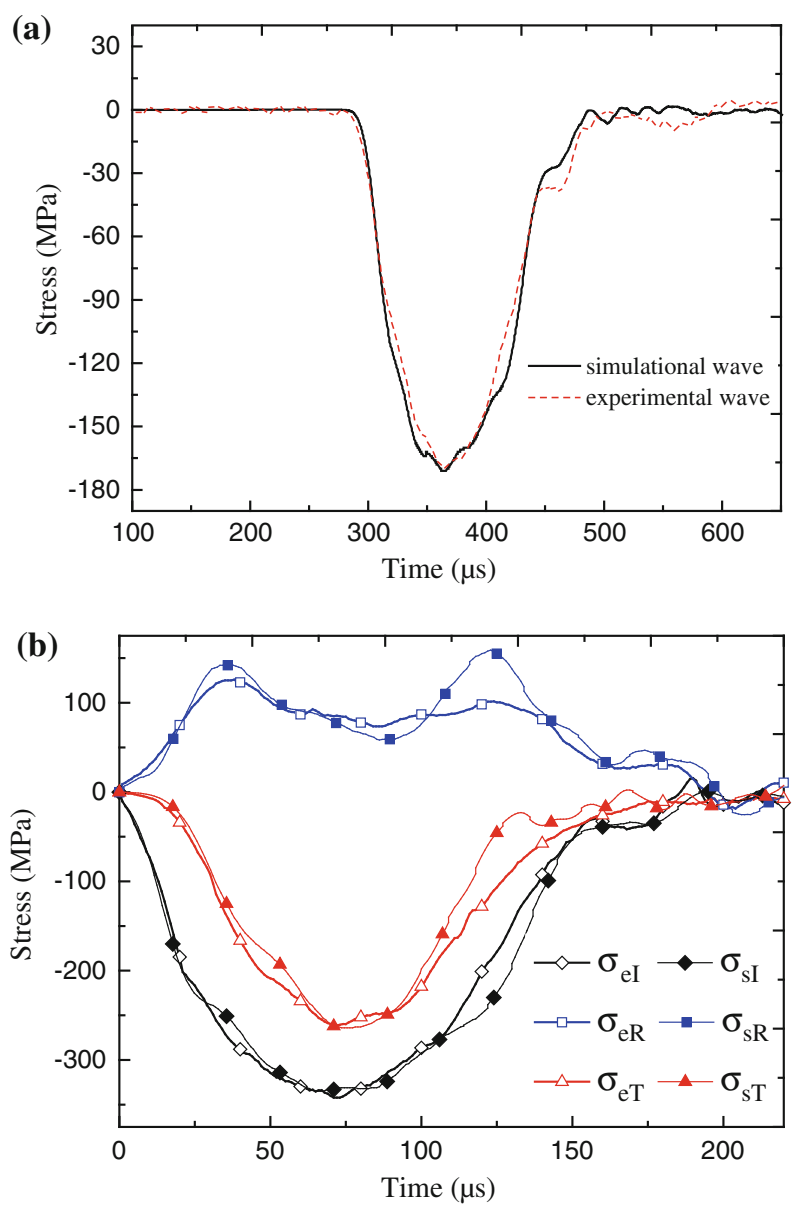

Fig. 3 Comparison of waves obtained by simulation and experiment: a incident waves obtained by simulation and experiment; $\mathbf{b}$ testing waves obtained by simulation and experiment

Figure $2 \mathrm{~b} 2$ shows the stress waves obtained under this modified model. It can be seen that the stress signals of the incident bar do not show a similar reflected extension wave to that in Fig. 2a2, and the amplitudes of the incident and transmitted waves are nearly equal. Further investigation of the detailed view of the contact interface shows that the contact force has a uniform distribution at the contact interface, which means that the wave transmission condition between bars is fine and the contact problem has been solved. The numerical conclusion has shown that complete contact at the contact interface is necessary for the SHPB test.

Figure 3a shows a comparison of the incident waves obtained by the simulation and experiment. They are both measured at a location $1 \mathrm{~m}$ away from the free end of the incident bar under the same impact velocity of $10 \mathrm{~m} / \mathrm{s}$. The simulated wave is almost identical to the real wave.

To further validate the capability of this numerical method to reproduce the dynamic response of the rock in the SHPB test, numerical waves obtained from a particle

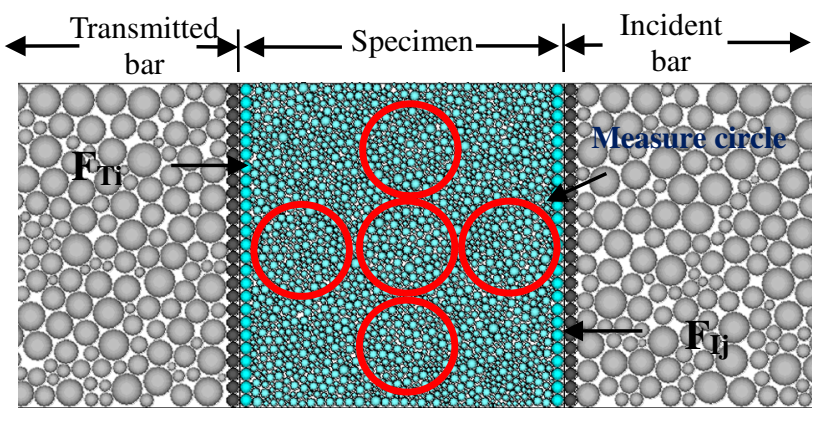

Fig. 4 Particle model of the specimen

model with carefully selected micro-parameters were compared with experiment waves. A detailed description of the calibration process will be given later and, for the same reason as above, to ensure that the loading wave transmits between the bars and the specimen successfully, particles at the two lateral boundaries of the specimen have also been aligned to the corresponding particles of the bars shown in Fig. 4.

The waveform comparison is shown in Fig. 3b, which indicates that there is good consistency between the simulated and experimental waves, especially before the specimen reaches the peak stress. A slight discrepancy in the post-peak stage indicates that the bonded-particle model for rock possesses a more brittle mechanical property than the tested granite specimen in the post-peak stage. On the other hand, it also provides evidence that using the special shape striker enables us to test the post-peak behavior of the rock.

So far, the feasibility of the numerical SHPB system has been verified. On the one hand, the loading system can provide a stable loading wave which is close to reality; on the other hand, the bonded-particle model can possess a dynamic response that is very similar to that of the rock.

\section{Numerical SHPB Dynamic Experiment Based on PFC}

In reality, rock properties are various and some inevitable factors cause experimental errors, such as friction, noise disturbance in signals, and so on. These aspects definitely hinder the development of a general analysis of the SHPB system. Hereafter, to gain a comprehensive understanding of the system's own attributes beyond the limitations of the experiments, based on the above numerical SHPB system, a particle specimen with representative micro-parameters was tested, with a particle radius of $0.3-0.9 \mathrm{~mm}$, porosity of 0.02 , normal stiffness of $80 \times 10^{9} \mathrm{~N} / \mathrm{m}$, shear stiffness of $40 \times 10^{9} \mathrm{~N} / \mathrm{m}$, particle density of $2,500 \mathrm{~kg} / \mathrm{m}^{3}$, and normal and shear bond strength of $100 \pm 50 \mathrm{MPa}$. The diameter of the specimen is $50 \mathrm{~mm}$ and the slenderness ratio is 1.0 . 
To inspect the validity of the numerical dynamic experiment and search for an appropriate stress monitoring method, the stress wave propagation in the bars and stress equilibrium in the specimen were investigated first.

\subsection{Stress Wave Propagation in Bars}

In order to monitor the stress wave propagation, two measuring circles with radius $0.01 \mathrm{~m}$ were assigned on the incident bar and transmitted bar at 0.8 and $0.1875 \mathrm{~m}$ from the contact interfaces between the specimen and the corresponding bars, respectively. Figure 5 shows the stress signals obtained through the two measuring circles under different impact velocities.

It can be seen from the graph that, with the increase of impact velocity and the amplitude of the incident wave, on the one hand, the amplitude of the reflected wave clearly rises, which means that the strain rate of the specimen during the loading process is heightened; on the other hand, the amplitude of the transmitted wave rises with an earlier peak time and shorter duration, generally indicating that the peak strength of the specimen is higher and the loading time of the specimen becomes shorter.

In addition, two typical patterns can be realized among these reflected waves, as the tail of reflected wave 1 possesses a negative value, while the other reflected waves present an extension wave along their whole section. From further investigation of the wave propagation shown in Fig. 6, it can be found that, under an impact velocity of $5 \mathrm{~m} / \mathrm{s}$, there is, closely following the reflected extension wave, a compressive wave propagating along the incident bar (Fig. 6a); on the contrary, this compressive wave cannot be found under an impact velocity of $8 \mathrm{~m} / \mathrm{s}$ (Fig. 6b). It can be explained that, under a relatively small impact velocity, the specimen cannot be damaged completely during the loading period (i.e., the rising section of the incident wave) and a certain amount of strain energy is

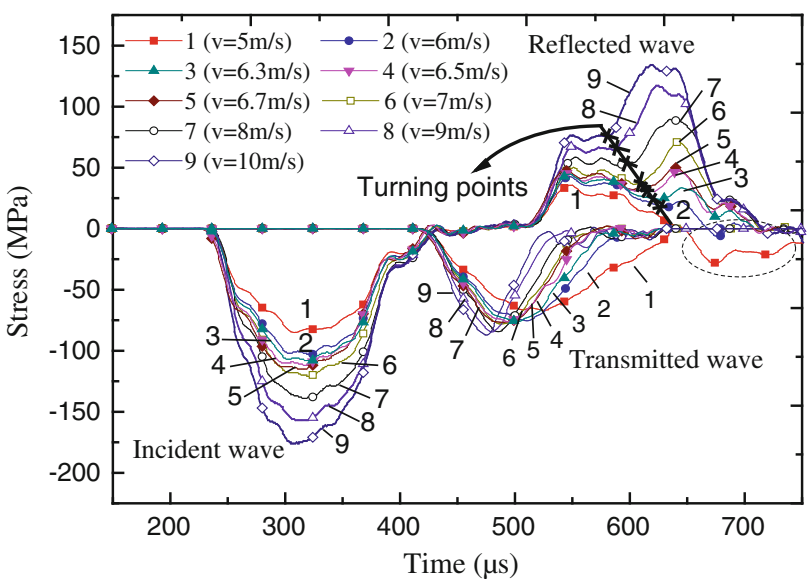

Fig. 5 Stress wave signals under different impact velocities stored in the specimen at first, then, during the unloading period (i.e., the falling section of the incident wave), the stored energy will be released gradually into the bars, as what we call a spring-back phenomenon, which leads to the reverse compressive wave. However, under a relatively large impact velocity, the specimen will be destroyed during the loading phase and the stored energy will be released instantaneously as kinetic energy, surface energy, or another type of energy, so this compressive wave will not appear.

It is also found that, with the increase in impact velocity, the reflected wave tends to be flat, which means that the strain rate of the specimen is nearly constant. But as the impact velocity continues to increase, a protuberance higher than the front platform appears in the later part of the reflected wave and becomes increasingly apparent. A rough inference can be made that constant strain rate cannot be guaranteed during the whole loading process in these cases.

\subsection{Stress Equilibrium in the Specimen}

In the SHPB laboratory test, due to the difficulties in monitoring the axial stress and strain of the specimen directly, they are usually obtained based on the abovementioned calculation method, in which the incident wave, reflected wave, and transmitted wave are substituted in Eqs. 1-3. By contrast, in the numerical simulation, the monitoring of stress and strain at any designated position can be conveniently achieved through built-in or selfdefined measurement functions. The stresses at the specimen's two ends can be gained by recording the contact force of the particles at the bar/specimen contact interfaces and then calculating according to the following equations:

$\sigma_{\mathrm{SI}}=\frac{\sum_{j=1}^{N_{\mathrm{I}}} F_{I j}}{2 r \delta} \sigma_{\mathrm{ST}}=\frac{\sum_{i=1}^{N_{\mathrm{T}}} F_{T i}}{2 r \delta}$

where $F_{I j}$ and $F_{T i}$ represent the axial contact force of particle $j$ at the specimen's incident end and particle $i$ at the transmitted end, respectively; $N_{\mathrm{I}}$ and $N_{\mathrm{T}}$ denote the total number of the specimen's particles coming into contact with the incident bar and transmitted bar, respectively; $\sigma_{\mathrm{SI}}$ and $\sigma_{\mathrm{ST}}$ represent the stresses at the specimen's incident end and transmitted end, respectively; $r$ represents the radius of the specimen; and $\delta$ represents the thickness of the particles.

On the other hand, according to the SHPB theory, the stress of the specimen at the transmitted end can be expressed by transmitted wave $\sigma_{\mathrm{T}}$, while the stress of the specimen at the incident end can be expressed by the sum of the incident wave and the reflected wave $\sigma_{\mathrm{I}}+\sigma_{\mathrm{R}}$. Taking the case under an impact velocity of $8 \mathrm{~m} / \mathrm{s}$ as an example, Fig. 7 shows the stresses at the transmitted end 
(a)

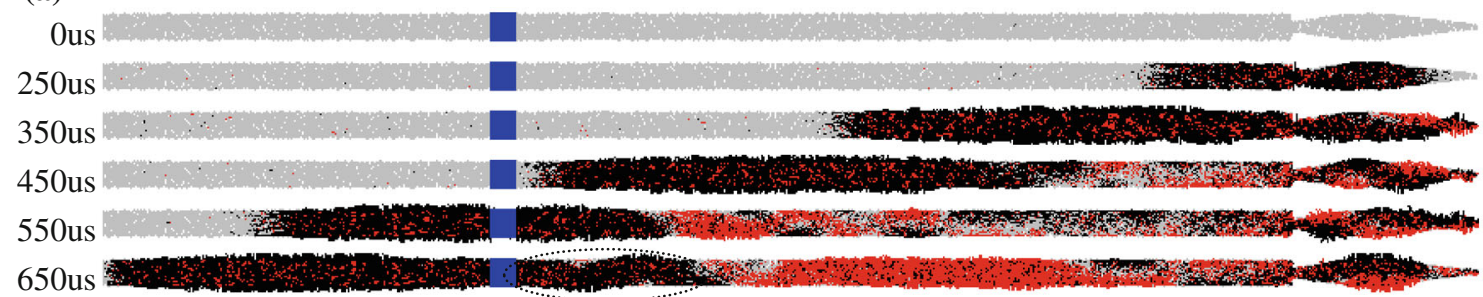

(b)

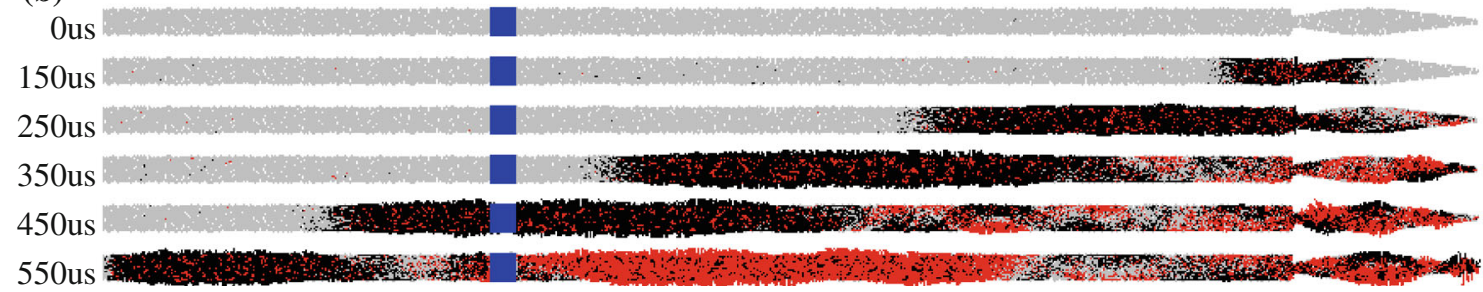

Fig. 6 Stress wave propagation in bars under different velocities: a impact velocity $v=5 \mathrm{~m} / \mathrm{s}$; b impact velocity $v=8 \mathrm{~m} / \mathrm{s}$

$\sigma_{\mathrm{T}}, \sigma_{\mathrm{ST}}$ and stresses at the incident end $\sigma_{\mathrm{I}}+\sigma_{\mathrm{R}}, \sigma_{\mathrm{SI}}$ obtained through theoretical calculation and direct measurement, respectively. It can be seen that the results from these two approaches are quite consistent. Thus, the reliability of each approach is mutually confirmed. But comparatively speaking, direct measurement without wave translation along the time axis and superposition in the stress amplitude is a simpler and more intuitive way to determine the stresses at the specimen's ends. Therefore, in the following work to obtain the stresses in the specimen, the direct monitoring approach is adopted.

Stress equilibrium is essential to ensure the validity of the SHPB test. From this point, the stress equilibrium factor $\eta$ was calculated through Eq. 5 to evaluate the stress balance level in the specimen. The calculated results under impact velocities of 8 and $5 \mathrm{~m} / \mathrm{s}$ are shown in Fig. 8a and $\mathrm{b}$, respectively.

$\eta=\frac{2\left(\sigma_{\mathrm{SI}}-\sigma_{\mathrm{ST}}\right)}{\sigma_{\mathrm{SI}}+\sigma_{\mathrm{ST}}}$

It can be seen from Fig. 8a that the stress equilibrium factor has gone through a number of different stages during the loading process. With reference to the start/stop moments of each stage, the evolution of the stress state in the specimen can be described as follows: (1) at time $t_{\mathrm{i}}$, the incident wave reaches the bar/specimen interface, and part of it is reflected, while another part continues propagating to the specimen's transmitted end. For the stress at the transmitted end of the specimen, $\sigma_{\mathrm{ST}}$ is still zero before the stress wave reaches the end, and the stress equilibrium factor remains at 2. (2) At time $t_{\mathrm{t}}$, the stress wave reaches the transmitted end and then moves back and forth based on the reflected/transmitted law. Under several wave reverberations like this, the stress equilibrium factor decreases gradually from 2 and tends to zero. (3) At time $t_{\mathrm{b}}$, the stress equilibrium factor approaches zero for the first time. Thereafter, the value of $\eta$ fluctuates slightly around zero, which means that the stress equilibrium is maintained to some extent within a certain stage. (4) At time $t_{\mathrm{p}}$, the stresses at the specimen's two ends reach the peak value. After that, the fluctuation of the stress equilibrium factor becomes dramatic, but the value still remains around zero, indicating that, although the bearing capacity of the specimen has reached its limit at the peak time, in a certain subsequent stage, the specimen can still bear the load as an entirety. (5) At time $t_{\mathrm{d}}$, the stress equilibrium factor decreases dramatically, implying that the integrity of the specimen has been severely damaged and, in this case, the stress wave cannot easily propagate back and forth in the specimen. In addition, because the falling edge of the incident wave has reached the specimen's incident end at this moment, i.e., an unloading wave acts around this end, the stress at the incident end becomes smaller and smaller compared to that at the other end. As a result, the stress equilibrium factor gradually declines to a negative value. Thus, the conclusion can also be drawn that the stress-strain relationship of the specimen obtained under this SHPB method is valid till time $t_{\mathrm{d}}$. (6) At time $t_{\mathrm{e}}$, the stress equilibrium factor reduces to -2 , indicating that the specimen is not in contact with the incident bar, but due to the time effect of wave propagation, there are still some particles at the specimen's transmitted end in contact with particles of the transmitted bar.

Comparing with Fig. 8a, it can be seen from Fig. $8 \mathrm{~b}$ that there is no sharp drop in the stress equilibrium factor at the later stage, indicating that the specimen can bear the load as a nearly intact entirety during the whole loading process, i.e., the specimen is not destroyed completely. For this case, the stress-strain curve is valid during the entire 

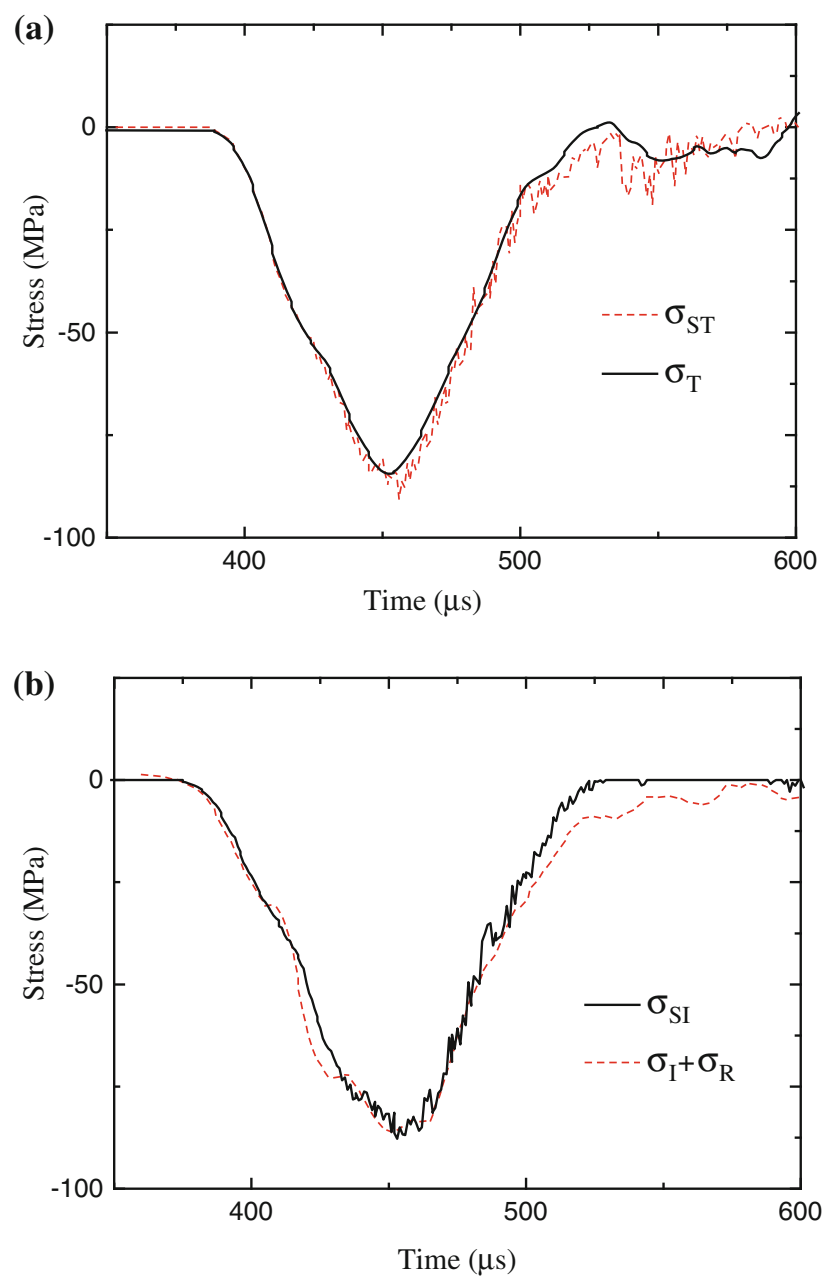

Fig. 7 Stresses at the specimen's two ends obtained by direct monitoring and theoretical calculation: a stress at the specimen's transmission end; $\mathbf{b}$ stress at the specimen's incident end

loading process. This is consistent with the discussion on the wave propagation in Sect. 4.1.

In conclusion, the stress equilibrium in the specimen can be achieved after several wave reverberations and maintained to some extent until the complete damage of the specimen at time $t_{\mathrm{d}}$. In other words, the stress-strain relationship of the specimen from its peak stress time $t_{\mathrm{p}}$ to time $t_{\mathrm{d}}$ is still valid and can reflect the post-peak mechanical behavior.

\subsection{Strain Rate Evolution of the Specimen}

The strain rate of the specimen recorded as $\dot{\varepsilon}_{\mathrm{R}}$ is usually calculated through Eq. 3 in the SHPB test, from which it is found that the reflected wave is able to give an intuitive image of the variation characteristics of the specimen's strain rate. On the other hand, the average strain rate within a certain area can be monitored directly through the
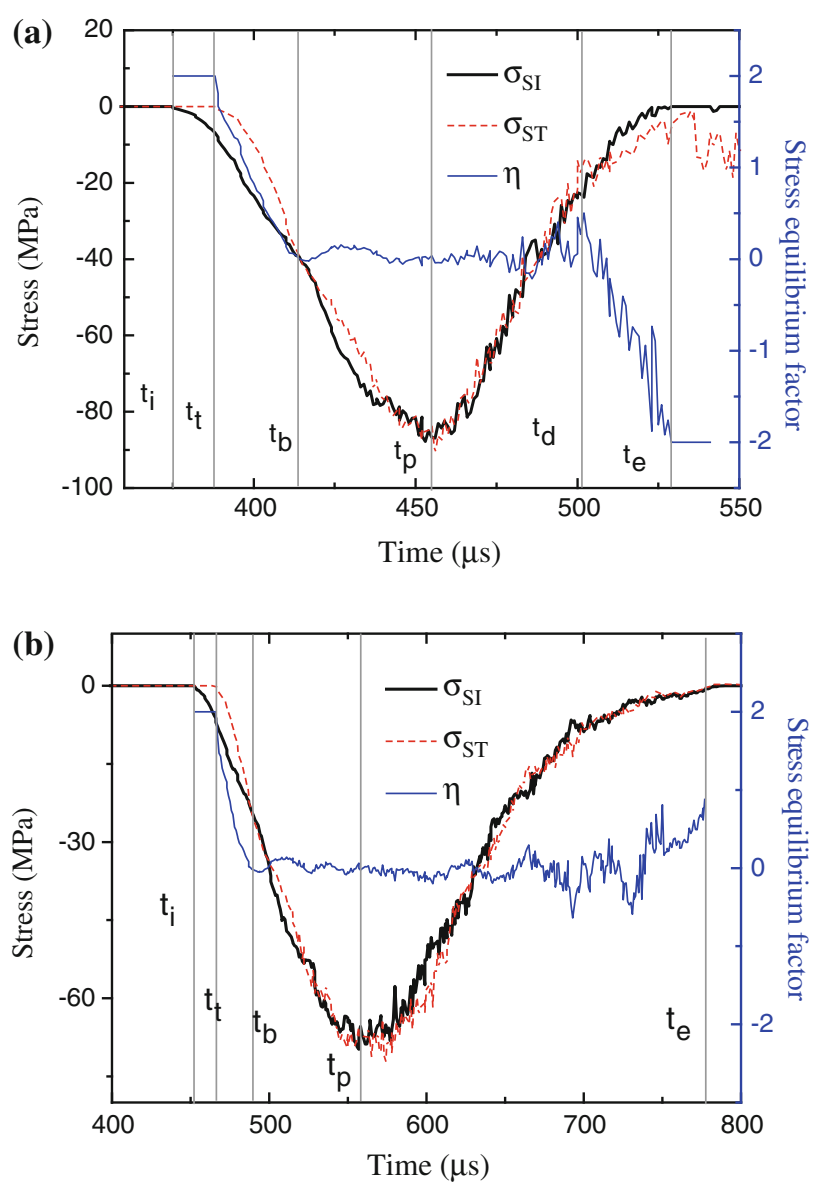

Fig. 8 Stress equilibrium at the specimen's two ends under different impact velocities: a impact velocity $v=8 \mathrm{~m} / \mathrm{s}$; b impact velocity $v=5 \mathrm{~m} / \mathrm{s}$

measuring circles in PFC. Through this method, the average of the strain rate obtained through the five measuring circles shown in Fig. 4 is represented as $\dot{\varepsilon}_{\mathrm{S}}$. The comparison with the strain rates determined through these two approaches under an impact velocity of $8 \mathrm{~m} / \mathrm{s}$ is shown in Fig. 9a.

It is found that there is a general consistency in the shape and magnitude of the time-history curves of $\dot{\varepsilon}_{\mathrm{R}}$ and $\dot{\varepsilon}_{\mathrm{S}}$, while the oscillation in the curve of $\dot{\varepsilon}_{\mathrm{R}}$ is bound up with the intrinsic attribute of the DEM. This means that these two approaches are both reliable in determining the strain rate of the specimen.

In order to gain a deeper understanding of the variation characteristics of the specimen's strain rate at different loading stages, the patterns of the incident wave, reflected wave, and stresses at the specimen's ends are compared, referencing the characteristic times which are determined according to the stress equilibrium factor. This is shown in Fig. 9b, in which the negative reflected wave is depicted for convenient comparison.

A clear relationship is found between the changing stages of the strain rate and the characteristic time 

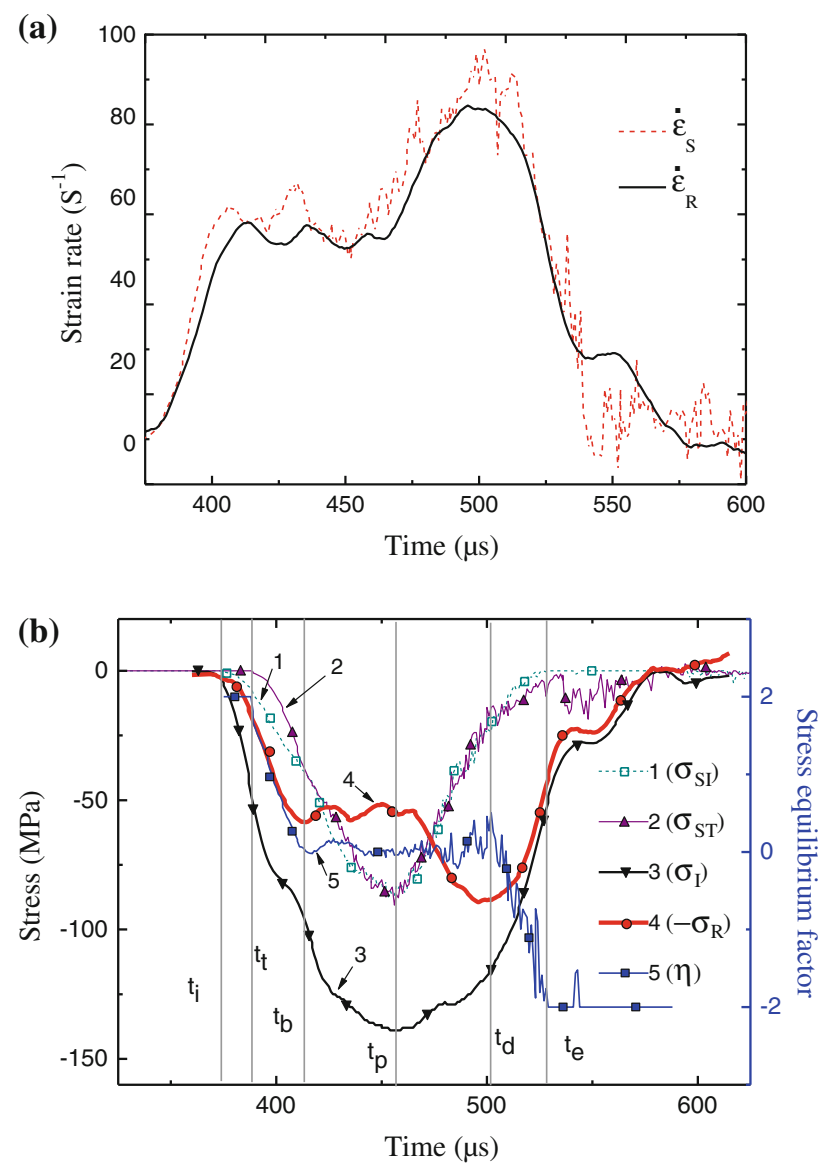

Fig. 9 Strain rate of the specimen under an impact velocity of $8 \mathrm{~m} / \mathrm{s}$ : a strain rate time-history curves obtained by direct monitoring and theoretical calculation; b variation characteristics of the specimen's strain rate

determined by the stress equilibrium factor. Combining the loading situation of the specimen, the following analysis can be made:

1. From time $t_{\mathrm{i}}$ to time $t_{\mathrm{b}}$, stress equilibrium has not been achieved and the axial inertia effect cannot be ignored.

As a result, the variation of the strain rate cannot be revealed by the reflected wave deduced from Eq. 3. In fact, within the time when the wave propagates back and forth through the specimen for the first time, there is no superposition in the reflected wave and the equation $\sigma_{\mathrm{R}}(t)=\lambda \sigma_{\mathrm{I}}(t)$ can be established when $\lambda$ is used to represent the reflection coefficient, so the reflected wave possesses a rising edge that is nearly consistent with the incident wave at this stage.

2. From time $t_{\mathrm{b}}$ to time $t_{\mathrm{p}}$, stress equilibrium has been achieved, the axial inertia effect can be ignored, and the variation of the strain rate can be revealed by the reflected wave. The reflected wave at this stage is nearly level in the figure, indicating that the strain rate remains approximately constant. It is worth noting that the appearance of this platform in the reflected wave requires some preconditions. Zhou et al. (2010) have discussed loading conditions for specimen deformation at a constant strain rate, concluding that, only when the loading stress and deformation stress in the specimen have the same changing pattern, can the specimen deform at a constant strain rate. From this point, it can be inferred that a constant strain rate in the specimen can be achieved under the half-sine loading wave generated by this special shape striker, which possesses a rising edge with a certain slope. This inference has just been proved by the results of this simulation.

3. From time $t_{\mathrm{p}}$ to time $t_{\mathrm{d}}$, the stress equilibrium factor still fluctuates around zero and the fluctuating margin becomes clearly larger, indicating that, after the peak stress on the one hand, the specimen still has the capacity to bear loading as an entirety; on the other hand, cracks in the specimen are developing and expanding dramatically, which affects the stress equilibrium of the specimen. Due to the constant accumulation of damage in the specimen, the equivalent elastic modulus of the specimen decreases and the reflected coefficient increases. Therefore, although the loading energy gradually reduces after the peak of the incident wave, the reflected wave is continuously rising at this stage. But just because of this decline in loading energy, the rise in the reflected wave cannot last indefinitely. At a certain stage, these two contradictory factors which affect the reflection evolution become balanced, and the rise in reflection tends to be moderate and ultimately stops. There is even a platform in the reflected wave after it experiences a rise, as shown in waves 8 and 9 in Fig. 5.

In addition, it can be seen from the graph that the peak stress time of the specimen corresponds to the turning point of the reflected wave, implying that the qualitative change of the macroscopic elastic properties caused by the quantitative accumulation of internal damage is co-instantaneous as the bearing capacity of the specimen reaches its limit. Xia et al. (2008) conducted a uniaxial compressive test on Barre granite under a high strain rate and obtained reflected waves which are similar to that in Fig. 9b. They regarded the starting point of the rapid rise in the reflected wave as the damage point and calculated the strain rate of the specimen according to the initial platform of the reflected signal. This is consistent with the above analysis.

4. From time $t_{\mathrm{d}}$ to time $t_{\mathrm{e}}$, the stress equilibrium factor decreases dramatically, i.e., the stress equilibrium steadily worsens, as a result of which the specimen can no longer bear loading as an entirety. But due to the duration of the damage development of the 
specimen, it is still in contact with part of the incident bar's particles. Therefore, the stress equilibrium factor has to experience this period to fall to -2 .

5. After time $t_{\mathrm{e}}$, the stress equilibrium factor has dropped to -2 and the contact force at the incident bar/ specimen interface becomes zero, meaning the two have entirely separated. As a result, the incident wave is reflected at this free interface and the reflected wave displays a similar decline-edge to it.

In summary, the reflected waves of specimens which are ultimately damaged during the impact loading, such as waves 2-9 shown in Fig. 5, can both be divided into two sections by the turning point, i.e., the platform stage and the ascent stage, and according to the above analysis, the turning point in each wave can be matched with the peak stress time. Furthermore, with the increase of impact velocity, the level of the platform increases gradually, while that of the ascent stage increases more dramatically. Correspondingly, these waves can be classified as three types, listed sequentially with the increase of impact velocity: (1) the level of the ascent section is lower than that of the platform section (waves 2 and 3); (2) the two levels are nearly equal (waves 4 and 5); (3) the situation is the reverse of type 1 (waves 6-9). From this case, it can be inferred that, under a certain moderate impact velocity, the specimen can deform at a constant strain rate during almost the whole loading process.

\subsection{Failure Process of the Specimen}

From the above analysis, it is seen that the loading process can be effectively divided into several typical stages according to the characteristic time determined based on the variation of the stress equilibrium factor. Taking the case with an impact velocity of $8 \mathrm{~m} / \mathrm{s}$ as an example, the velocity field, stress field (represented by the particle contact force), and crack propagation in the specimen at each characteristic time are shown in Fig. 10.

It can be seen from the Fig. 10 that: at time $t_{\mathrm{i}}$, particles at the specimen's incident end start moving and the contact forces of the particles at the incident bar/specimen interface begin to rise; at time $t_{\mathrm{t}}$, particles at the specimen's transmitted end gain speed and contact forces are visible at this end, but the magnitudes of the velocity and force are both significantly smaller than that of their counterparts at the other end; at time $t_{\mathrm{b}}$, the patterns of velocity and contact force in the specimen are both uniform and a small quantity of micro-cracks can be detected; at time $t_{\mathrm{p}}$, the velocity field in the specimen is disordered and the quantity of micro-cracks increases significantly, but the contact forces at the specimen's two ends are still approximately the same magnitude and the stress field remains nearly homogeneous; at time $t_{\mathrm{d}}$, the directions of the particle velocities in the specimen separate up and down, while the contact forces at the boundaries and interior of the specimen both become non-uniform with the continuous increase in the quantity of micro-cracks; at time $t_{\mathrm{e}}$, the separation tendency in the velocity field becomes more apparent, macrofissures can be detected clearly, and there is almost no contact force between the particles at the incident bar/ specimen interface. From the separation pattern in the velocity field, it can be inferred that the form of the specimen's failure is a splitting failure, which is consistent with the testing results ( $\mathrm{Li}$ et al. 2005).

In order to comparatively analyze the loading process of the specimen, characteristic times under different impact velocities are extracted using the above method. For comparative purposes, every $t_{\mathrm{i}}$ is regarded as the original time and the corresponding relative time is presented in Table 1.

It can be seen from Table 1 that: (1) under different impact velocities, it takes nearly the same time for the stress waves propagating from the specimen's incident end to its transmitted end, from which the wave speed in the specimen can be inferred to be around 3,500 m/s; (2) under different impact velocities, the relative times at which stress equilibrium is achieved in the specimen are very similar at about $40 \mu \mathrm{s}$, meaning that the stress wave propagates back and forth in the specimen three times; (3) with the increase in impact velocity, the times at which the stress reaches its peak, the specimen loses its integrity, and the loading process terminates are all advanced.

\section{Strain Rate Effect}

\subsection{Experiment}

Based on the above knowledge, several laboratory experiments on granites were conducted to check the varying pattern of reflected waves and serve for further understanding of the mechanism of the strain rate effect using the test device shown in Fig. 1. Six typical waves are shown in Fig. 11 and in order to facilitate the following simulation, the impact velocities were recorded by a laser timing device with a digital display.

It can be seen from Fig. 11 that the experiment wave patterns are very consistent with the above simulation results, i.e., the reflected wave can be divided into two sections and classified as three types. Moreover, under a moderate impact velocity (wave 3 ), the reflected wave seems to be nearly at a platform during the whole valid testing period. 
(a)
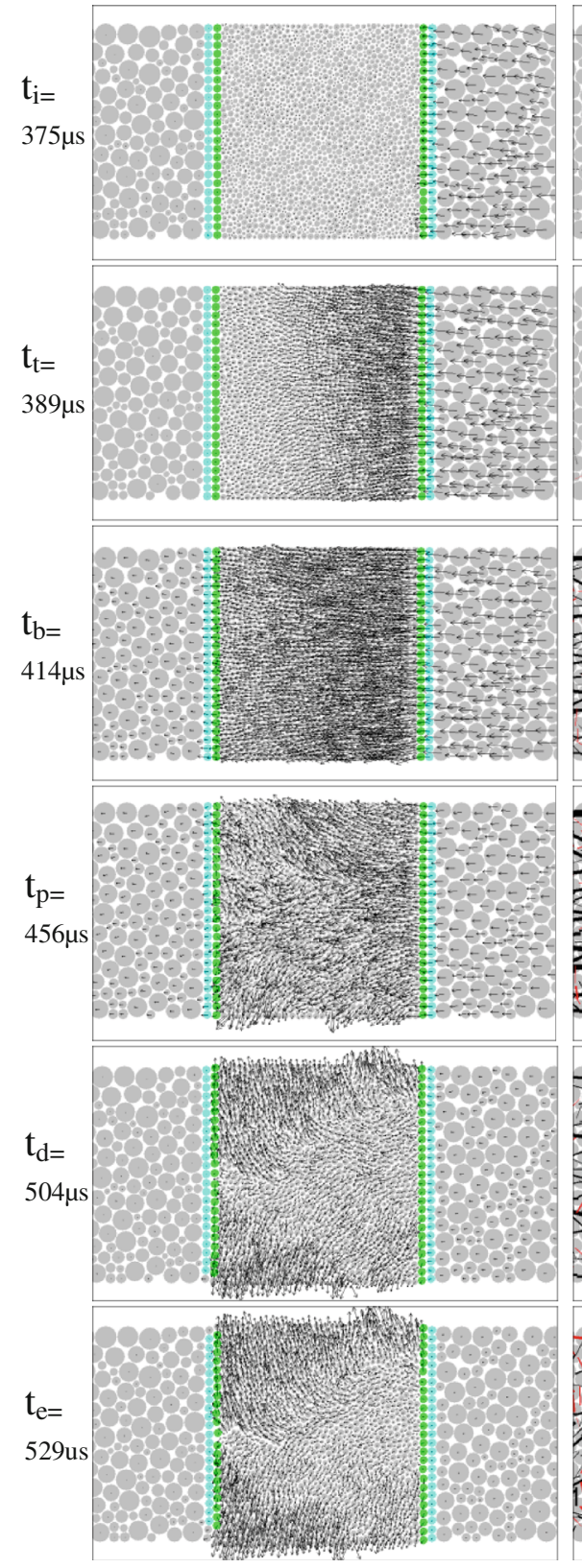

(b)
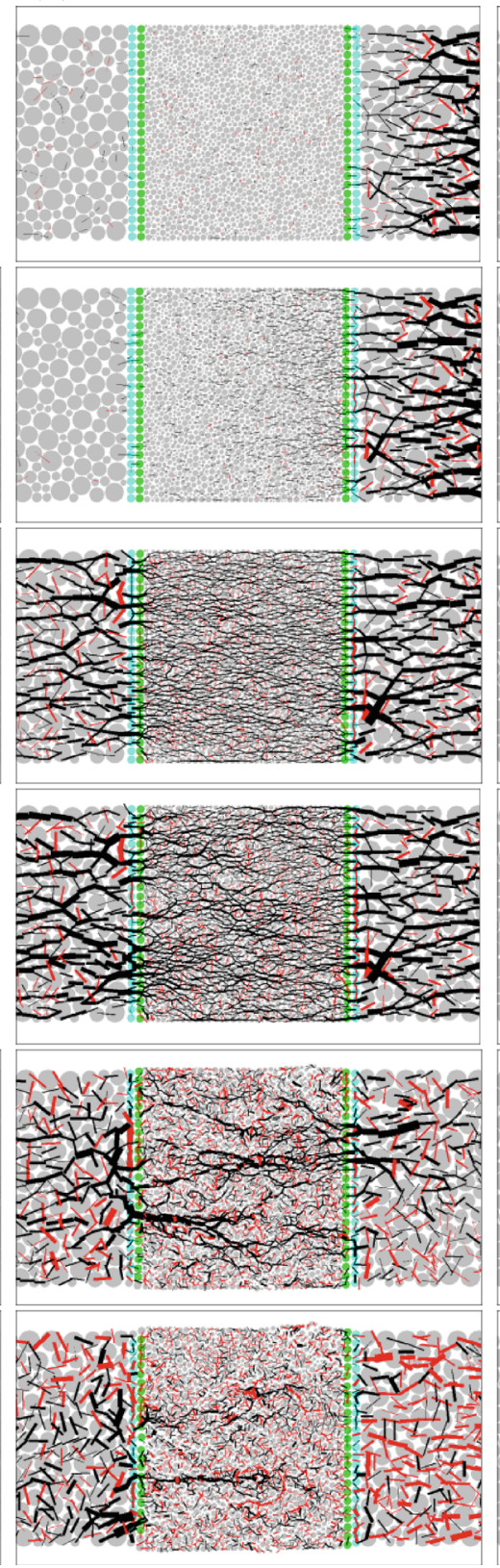

(c)
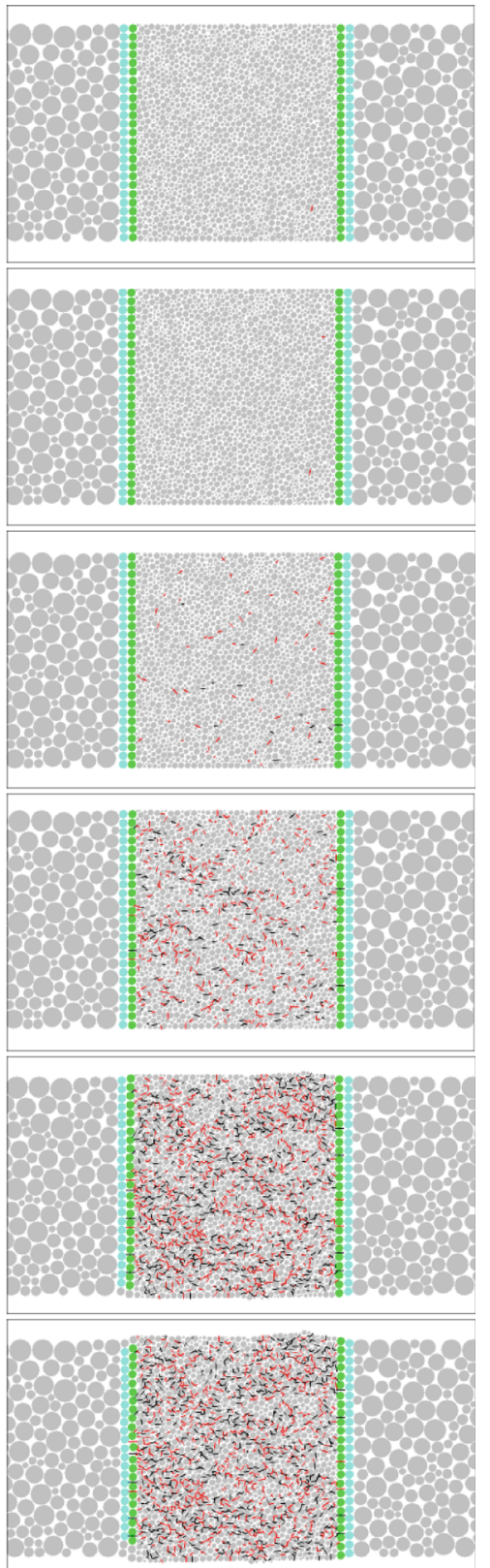

Fig. 10 The loading process of the specimen under an impact velocity of $8 \mathrm{~m} / \mathrm{s}$ : a velocity evolution in the specimen; $\mathbf{b}$ contact force evolution in the specimen; $\mathbf{c}$ micro-crack evolution in the specimen

\subsection{Parameter Calibration}

According to the above testing results, the micro-parameters of the particles were calibrated. The calibrating process can be divided into two steps. Firstly, as the discrepancy between the dynamic and static elastic modulus of a particle model is small, the micro-deformation parameters, including the normal and shear stiffness, were calibrated through numerical static uniaxial compression tests to ensure that the model possesses the same elastic modulus and Poisson's rate as the granite specimen (Potyondy and
Cundall 2004; Wang and Tonon 2009). Then, in consideration of the heterogeneity in rock properties, microstrength parameters including the normal bond strength and shear bond strength were assumed to obey a normal distribution. For the variability in the distribution pattern of the micro-strength parameter which determines the heterogeneity of the models and ratio of the contact-bond shear $\left(\tau_{\mathrm{c}}\right)$ to normal strength $\left(\sigma_{\mathrm{c}}\right)$, there are infinite groups of micro-strength parameters which ensure that the model possesses the same dynamic strength under a certain impact velocity. In spite of this, models using different 
Table 1 Characteristic time under different impact velocities

\begin{tabular}{llrrrrrl}
\hline Impact velocity $(\mathrm{m} / \mathrm{s})$ & \multicolumn{7}{c}{ Time $(\mu \mathrm{s})$} \\
\cline { 3 - 8 } & & $t_{\mathrm{i}}$ & $t_{\mathrm{t}}$ & $t_{\mathrm{b}}$ & $t_{\mathrm{p}}$ & $t_{\mathrm{d}}$ & $t_{\mathrm{e}}$ \\
\hline 5 & Absolute time & 452 & 467 & 490 & 551 & - & 772 \\
& Relative time & 0 & 15 & 38 & 99 & - & 320 \\
6 & Absolute time & 418 & 432 & 455 & 517 & - & 668 \\
& Relative time & 0 & 14 & 37 & 99 & - & 250 \\
7 & Absolute time & 392 & 405 & 432 & 475 & 523 & 552 \\
& Relative time & 0 & 13 & 40 & 83 & 131 & 160 \\
8 & Absolute time & 375 & 389 & 414 & 456 & 504 & 529 \\
& Relative time & 0 & 14 & 39 & 81 & 129 & 154 \\
9 & Absolute time & 360 & 374 & 400 & 433 & 480 & 508 \\
& Relative time & 0 & 14 & 40 & 73 & 120 & 148 \\
10 & Absolute time & 348 & 361 & 389 & 417 & 464 & 486 \\
& Relative time & 0 & 13 & 41 & 69 & 116 & 138 \\
\hline
\end{tabular}

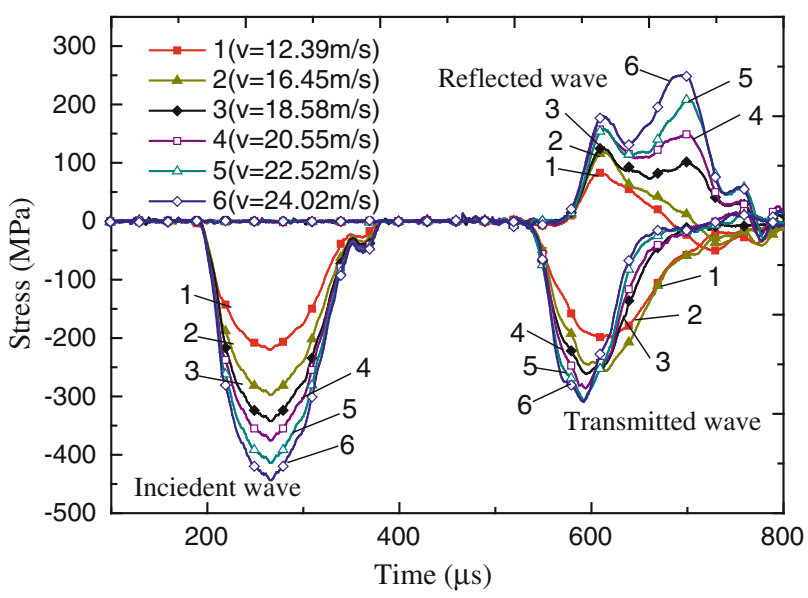

Fig. 11 Experimental stress waves under different impact velocities

combinations of micro-parameters may display different strain rate effects. Therefore, four groups of micro-strength parameters were calibrated based on test wave 3 in Fig. 11 to investigate the influence of the micro-strength ratio $\left(\tau_{\mathrm{c}} / \sigma_{\mathrm{c}}\right)$ and distribution pattern on the strain rate effect and search for the optimal group of micro-parameters. The micro-parameters of the numerical models and the static macro-parameters of the granite specimen and models are presented in Table 2.

According to the discussion in Sect. 4, to determine the simulational stress-strain curve of the specimen, the endpoints of the curves are determined by each $t_{\mathrm{d}}$, and the stress of the specimen is expressed by the average value of the stresses at the specimen's two ends, obtained by the direct monitoring method. The strain rate of the specimen is determined by the average value of the reflected wave from time $t_{\mathrm{b}}$ to time $t_{\mathrm{p}}$ and the strain equal to the integral of $\dot{\varepsilon}_{\mathrm{S}}$ times time is calculated by the following equation:
$\varepsilon_{\mathrm{S}}(N)=\sum_{n=0}^{N} \dot{\varepsilon}_{\mathrm{S}}(n) \cdot \Delta T(n)$

where $n$ denotes a time-step, $N$ denotes the current timestep and $\Delta T(n)$ represents the interval time under timestep $n$.

The stress-strain curves obtained by experiment and simulation under an impact velocity of $18.58 \mathrm{~m} / \mathrm{s}$ are shown in Fig. 12. It can be seen that they show good agreement in the pre-peak region, but the numerical models are more brittle after the peak. However, the maximum stresses of the numerical models fit the experimental result quite well. This guarantees the comparability of the models' strain rate effects. In addition, the relative smoothness of the simulated curves may serve to demonstrate the adaptability of the special shape striker in the rock dynamic SHPB test, which can be an improved experimental approach for eliminating oscillation that exists in the dynamic stress-strain response of rocks and other brittle materials.

To further investigate the loading process of the granite specimen, characteristic times $t_{\mathrm{b}}, t_{\mathrm{p}}$, and $t_{\mathrm{d}}$ were determined by the previous method and found to be 37,74 , and $128 \mu$ s, respectively; the corresponding points in the testing stressstrain curve have been marked in Fig. 12. The failure evolution was also captured by a high-speed camera, which was used at a frame rate of 100,000 frames per second. The camera was triggered by a transistor-transistor logic (TTL) level signal generated by the oscilloscope synchronously with the incident signal. In this way, the loading time and images can be correlated after removing the slight trigger delay. The time when the incident wave reached the specimen $t_{\mathrm{i}}$ was regarded as the starting time. Images with time stamps are shown in Fig. 13 (the incident bar is on the right).

From Fig. 13, it can be seen that changes on the surface of the specimen are almost indistinguishable before $48 \mu$ s. Extremely tiny cracks can be detected along the central loading axis from 68 to $88 \mu \mathrm{s}$, during which time the specimen experienced its peak stress. After that, the microcracks propagated further along the loading axis and ultimately coalesced as one easily visible linear crack till $128 \mu \mathrm{s}$. At this time, the failure of the specimen has developed to be at a certain macroscopic scale. But as this failure was just localized on the surface of the specimen, the specimen can still be treated as a whole bearing entity and its stress equilibrium state was little affected. Therefore, the stress-strain relationship till this time is valid and the section obtained after the peak stress may reflect the dynamic post-peak behavior of the specimen.

As the failure gradually developed into the interior of the specimen from 148 to $208 \mu \mathrm{s}$, the surface crack 
Table 2 Micro-parameters of numeric models and static macro-parameters of granite specimen and models

\begin{tabular}{|c|c|c|c|c|c|c|c|}
\hline \multicolumn{5}{|c|}{ Micro-parameters (calibrated based on test wave 3 ) } & \multicolumn{3}{|l|}{ Macro-parameters } \\
\hline \multicolumn{2}{|c|}{ Particle radius $(\mathrm{mm})$} & \multicolumn{3}{|l|}{$0.3-0.9$} & & Granite & Models \\
\hline \multicolumn{2}{|l|}{ Porosity } & \multicolumn{3}{|l|}{0.02} & Elastic modulus (GPa) & 68 & 68 \\
\hline \multicolumn{2}{|c|}{ Normal stiffness (N/m) } & \multicolumn{3}{|l|}{$176 \times 10^{9}$} & Poisson's rate & 0.2 & 0.2 \\
\hline \multicolumn{2}{|c|}{ Shear stiffness $(\mathrm{N} / \mathrm{m})$} & \multicolumn{3}{|l|}{$88 \times 10^{9}$} & Density $\left(\mathrm{kg} / \mathrm{m}^{3}\right)$ & 2,610 & 2,610 \\
\hline \multicolumn{2}{|c|}{ Particle density $\left(\mathrm{kg} / \mathrm{m}^{3}\right)$} & \multicolumn{3}{|l|}{2,664} & Static compression strength (MPa) & 152 & 231 (Model A) \\
\hline- & Model A & Model B & Model C & Model D & & & 206 (Model B) \\
\hline$\sigma_{\mathrm{c}}(\mathrm{MPa})$ & $220 \pm 0$ & $150 \pm 0$ & $265 \pm 100$ & $200 \pm 100$ & & & 201 (Model C) \\
\hline$\tau_{\mathrm{c}}(\mathrm{MPa})$ & $220 \pm 0$ & $1,200 \pm 0$ & $265 \pm 100$ & $1,600 \pm 800$ & & & 168 (Model D) \\
\hline
\end{tabular}

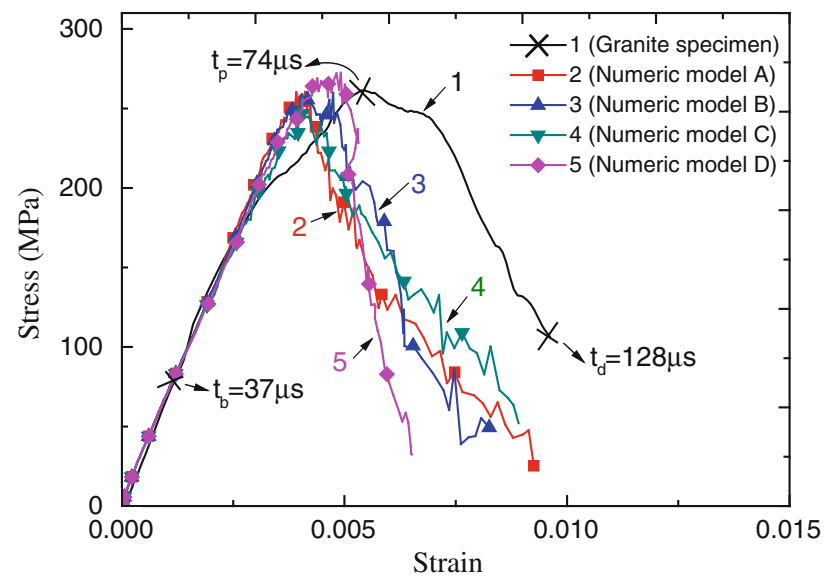

Fig. 12 Comparison of stress-strain curves obtained by an experiment and simulations under an impact velocity of $18.58 \mathrm{~m} / \mathrm{s}$

developed into a fracture which possessed a certain depth and finally split the specimen into two halves. As the integrity of the specimen was being disrupted at this stage, the stress equilibrium was also affected to some extent and the validity of the test is difficult to ensure, especially in the case of more violent damage under higher impact velocity.

At the last stage (368-968 $\mu$ s), the separated two parts moved upwards and downwards, respectively, and the fissure between them grew increasingly wide. From this phenomenon, it can be inferred that tension failure is the main mode of destruction for the granite specimen under uniaxial dynamic compression. These conclusions are consistent with the simulation results. So far, the applicability of using the special striker to obtain dynamic and complete stress-strain curves of the rock has been demonstrated by both the numerical simulation and the experiment.

\subsection{Influence Factors on the Strain Rate Effect}

From Fig. 12 and Table 2, it can be seen that although the dynamic strengths of the models are all consistent with that of the granite specimen under an impact velocity of $18.58 \mathrm{~m} / \mathrm{s}$, their static strengths are quite different. This generally demonstrates that the micro-strength ratio $\left(\tau_{\mathrm{c}} / \sigma_{\mathrm{c}}\right)$ and distribution pattern can affect the enhanced tendency in strength under a high strain rate. To further investigate the dynamic response of the particle specimens, numerical simulations are conducted under the other impact velocities mentioned in the above experiments. The dynamic increase factor (DIF), defined by the ratio of the dynamic strength to the quasi-static strength in uniaxial compression, is used to measure the strain rate effect on the strength of the models and granite specimens. The simulated and experimental results are demonstrated in Fig. 14a, except for the case of an impact velocity of $12.39 \mathrm{~m} / \mathrm{s}$, in which the specimen was not damaged.

Figure 14a shows that the dynamic compressive strengths obtained by both laboratory and numerical experiments increase with the strain rate, but the rising tendency, i.e., the strain rate effect, in the numerical results is apparently lower than that in the experiments. Furthermore, the DIF is also distinctly different among the numerical models. In the following work, these numerical results are compared to analyze the influence mechanism.

\subsubsection{Effects of the Micro-Strength Ratio}

Comparing the results of models $\mathrm{A}$ and $\mathrm{B}$, it can be seen that the strength of the model with a higher micro-strength ratio is more sensitive to the strain rate. In fact, this can be attributed to the "structure" effect, i.e., the existence of lateral confinement, which has been demonstrated in many papers as a crucial factor causing a distinct increase in strength under a high strain rate ( $\mathrm{Li}$ and Meng 2003; Lu et al. 2010; Janach 1976). From this, based on the MohrCoulomb criterion, it can be further inferred that the extent of the influence of the strain rate on the specimen's strength is largely dependent on the slope of the material's strength envelope. Several simulations have been performed using contact-bonded material, in which it was found that the ratio of the contact-bond shear to normal strength $\tau_{\mathrm{c}} / \sigma_{\mathrm{c}}$ affects the slope of the strength envelope. As the ratio $\tau_{\mathrm{c}} / \sigma_{\mathrm{c}}$ increases, the slope of the strength envelope 

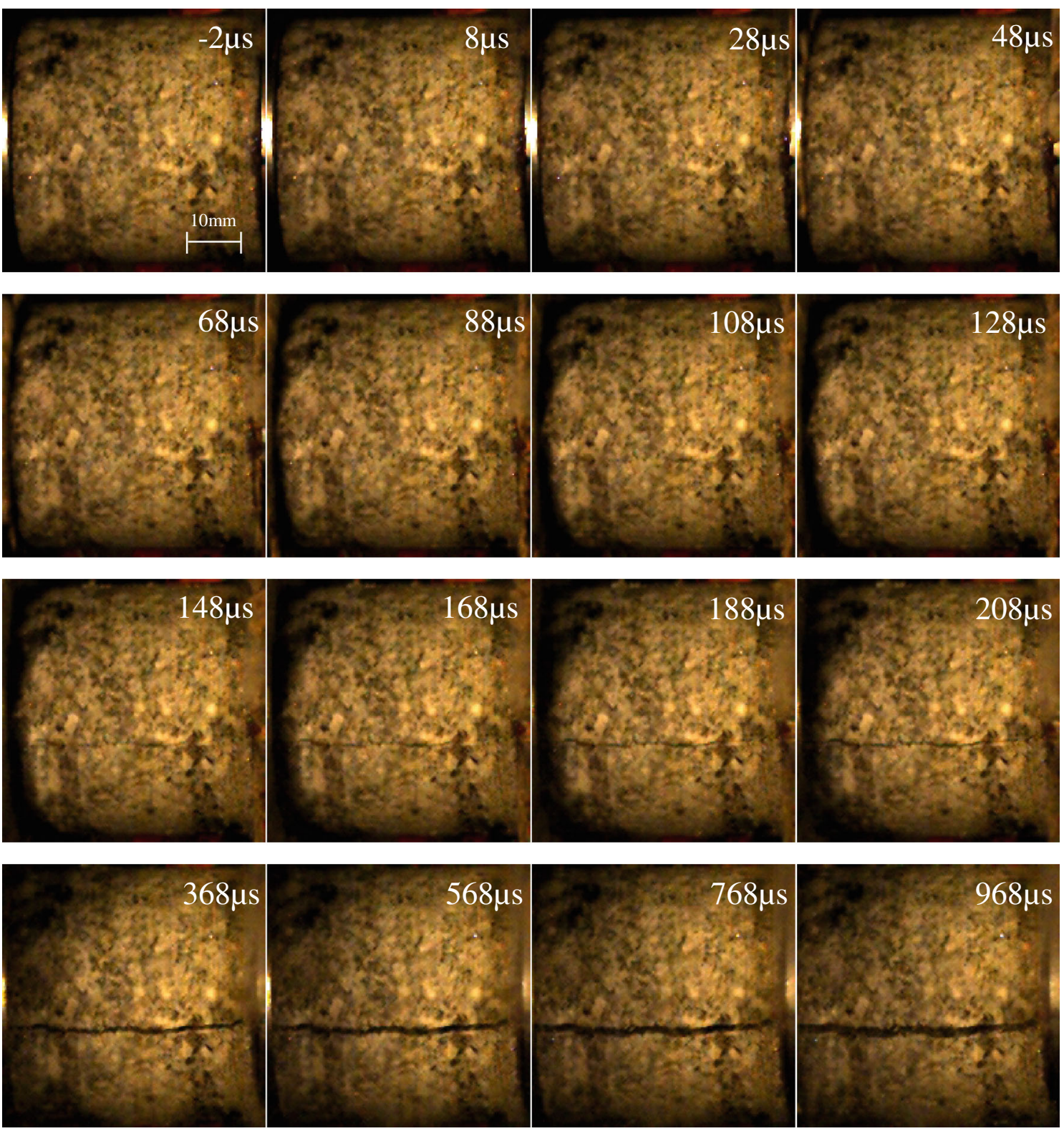

Fig. 13 High-speed photographs of the failure process of a granite specimen under an impact velocity of $18.58 \mathrm{~m} / \mathrm{s}$

increases (Itasca 2008). Therefore, the DIF of the model with a higher micro-strength ratio is larger, which is confirmed by Fig. 14a. However, there is a practical limit to this ratio and the slope of the model's strength envelope cannot reach the level of granite. As a result, when only the micro-strength ratio is taken into account, compared with the experimental results, the DIF in the simulation is lower.

\subsubsection{Effects of Heterogeneity}

Compared with model $\mathrm{A}$, model $\mathrm{C}$, as a heterogeneous synthetic material generated by setting the standard deviations of the strength distributions to a high value, possesses a more apparent strain rate effect. This just demonstrates that the heterogeneity is an important factor influencing the strain rate effect, as mentioned in other works (Ma et al. 2010, 2011). This conclusion is also consistent with the experimental results, which show that the poor quality specimen had a larger increase in dynamic strength (Ma et al. 2010).

Guided by the above analysis, to guarantee that the model displays an approximate strain rate effect as similar as possible to the reality, the combined effect of heterogeneity and the micro-strength ratio is taken into account in model D. It can be seen from Fig. 14a that its DIF is much closer to the experimental results. Although it may magnify 

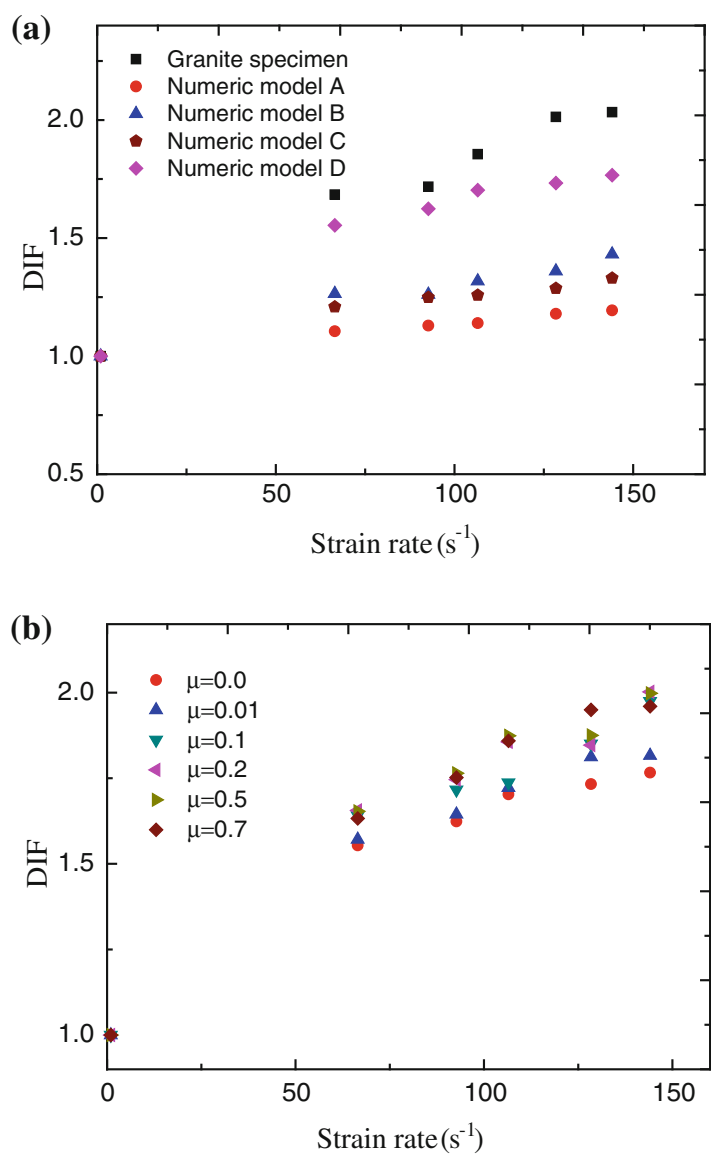

Fig. 14 Strain rate effect of granite specimens and numeric models in the SHPB test: a DIF of granite specimens and numeric models; b DIF of numerical model D under different frictional conditions

the effects of the two factors by ignoring other influencing factors which have not been considered in this work, this result can still be an instructive reference for the calibration of dynamic micro-parameters.

\subsubsection{Effects of Friction}

As the frictional effect is hard to eliminate completely, investigating the influence of friction on the testing results is significant for understanding the real dynamic properties of materials. Many previous studies have been performed on this subject (Li and Meng 2003; Hartley et al. 2007; Iwamoto and Yokoyama 2012). To examine this influence on the particle model, numerical dynamic tests were conducted on model $\mathrm{D}$ under different friction coefficients varying from $\mu=0.0$ to $\mu=0.7$, and the results are shown in Fig. 14b. It can be seen that the compressive strength is enhanced noticeably by the frictional effect, especially when $\mu$ is larger than 0.2 . This may be because the friction supplies another restraint to the lateral motion of the specimen. This conclusion is quite consistent with the results of Li and Meng (2003). It further demonstrates the feasibility of using the particle model to obtain a full account of the influencing factors in the SHPB test and indicates that the ends of the specimen should be well lubricated in the dynamic test.

\section{Conclusion}

1. A numerical dynamic experiment system with a special shape striker has been established based on PFC, which involves the generation of a realistic loading wave through simulating the actual impact process and the modification on the wave propagation condition by aligning the particles at the contact interfaces.

2. Numerical dynamic experiments have been conducted under different impact velocities. Through analysis of the stresses at the specimen's two ends, which are obtained in two different ways, including direct monitoring of the contact forces at the specimen/bars interfaces and theoretical calculation from the incident, reflected, and transmitted waves, the fundamental SHPB theories (i.e., one-dimensional wave theory and stress uniformity assumption) have been verified.

3. Detailed analysis has been conducted on the changing characteristics of the specimen's strain rate according to the pattern of the reflected waves. The results show that there is a clear relationship between the changing stages of the reflected waves and the characteristic time determined by the stress equilibrium factor. The turning point of the reflected wave shows good correspondence with the peak stress in the specimen. The patterns of the reflected waves under different impact velocities can be divided into three types and the specimen can deform at a constant strain rate during almost the whole loading process under an appropriate impact velocity.

4. A basic similarity has been found between the experimental and simulated results. Combining the consideration of the smoothness of the simulated stress-strain curves, this work can provide a simulational proof to demonstrate that the use of a special shape striker is a reliable testing method to obtain complete dynamic stress-strain curves for rocks, without apparent oscillation, which has been further demonstrated through investigating the stress equilibrium state and the failure evolution of the tested granite specimen.

5. Through the investigation of the influence of the micro-strength ratio $\left(\tau_{\mathrm{c}} / \sigma_{\mathrm{c}}\right)$ and distribution pattern on the DIF, lateral inertia confinement and heterogeneity have been demonstrated to be two important factors causing the increase of strength under a high strain rate. This recognition can guide the calibration of 
optimal micro-parameters. Though the DIF in the numerical model did not coincide closely with the test results at this stage, which may be due to the limitations of the 2D numerical model, ignorance of other influencing factors or an inherent defect in the laboratory test, the existence of a strain rate effect in the model provides a possibility for further work to improving the understanding of its micro-mechanism, which mainly refers to the influence of the micro-structure involving the particle size, particle shape, bond type, and so on, and, finally, to establish a closer unity between the microscopic and macroscopic scales.

Acknowledgments The work is financially supported by financial grants from the National Natural Science Foundation of China (50934006, 51274254, 41272304) and the National Basic Research Program of China (2010CB732004). The authors wish to acknowledge their financial contribution and convey their appreciation of the two organizations for supporting this basic research. The corresponding author also wants to express gratitude to the China Scholarship Council (CSC).

\section{References}

Al-Mousawi MM, Reid SR, Deans WF (1997) The use of the split Hopkinson pressure bar techniques in high strain rate materials testing. Proc Inst Mech Eng Part C 211:273-292

Bertholf LD, Karnes CH (1975) Two-dimensional analysis of the split Hopkinson pressure bar system. J Mech Phys Solids 23(1):1-19

Cai M, Kaiser PK, Suorineni F, Su K (2007) A study on the dynamic behavior of the Meuse/Haute-Marne argillite. Phys Chem Earth 32(8-14):907-916

Cotsovos DM, Pavlović MN (2008) Numerical investigation of concrete subjected to compressive impact loading. Part 2: parametric investigation of factors affecting behaviour at high loading rates. Comput Struct 86(1-2):164-180

Cundall PA, Strack ODL (1979) A discrete numerical model for granular assemblies. Géotechnique 29(1):47-65

Deluzarche R, Cambou B (2006) Discrete numerical modelling of rockfill dams. Int J Numer Anal Meth Geomech 30:1075-1096

Demirdag S, Tufekci K, Kayacan R, Yavuz H, Altindag R (2010) Dynamic mechanical behavior of some carbonate rocks. Int $\mathrm{J}$ Rock Mech Min Sci 47(2):307-312

Diederichs MS, Kaiser PK, Eberhardt E (2004) Damage initiation and propagation in hard rock during tunnelling and the influence of near-face stress rotation. Int J Rock Mech Min Sci 41(5):785-812

Frew DJ, Forrestal MJ, Chen W (2001) A split Hopkinson pressure bar technique to determine compressive stress-strain data for rock materials. Exp Mech 41(1):40-46

Hartley RS, Cloete TJ, Nurick GN (2007) An experimental assessment of friction effects in the split Hopkinson pressure bar using the ring compression test. Int J Impact Eng 34(10):1705-1728

Hazzard JF, Young RP (2004) Dynamic modelling of induced seismicity. Int J Rock Mech Min Sci 41(8):1365-1376

Hazzard JF, Young RP, Maxwell SC (2000) Micromechanical modeling of cracking and failure in brittle rocks. J Geophys Res 105(B7):16683-16697

Hentz S, Donzé FV, Daudeville L (2004) Discrete element modelling of concrete submitted to dynamic loading at high strain rates. Comput Struct 82(29-30):2509-2524
Itasca (2008) PFC2D: Particle flow code in 2 dimensions, version 4.0, user's manual. Itasca Consulting Group, Inc., Minneapolis, MN

Iwamoto T, Yokoyama T (2012) Effects of radial inertia and end friction in specimen geometry in split Hopkinson pressure bar tests: a computational study. Mech Mater 51:97-109

Janach W (1976) The role of bulking in brittle failure of rocks under rapid compression. Int J Rock Mech Min Sci Geomech Abstr 13(6): 177-186

Kolsky H (1949) An investigation of the mechanical properties of materials at very high rates of loading. Proc Phys Soc Lond Ser B 62:676-700

Kumar A (1968) The effect of stress rate and temperature on the strength of basalt and granite. Geophysics 33(3):501-510

Li XB, Gu DS (1994) Rock impact dynamics. Central South University of Technology Press, Changsha, pp 14

Li QM, Meng H (2003) About the dynamic strength enhancement of concrete-like materials in a split Hopkinson pressure bar test. Int J Solids Struct 40(2):343-360

Li XB, Lok TS, Zhao J, Zhao PJ (2000) Oscillation elimination in the Hopkinson bar apparatus and resultant complete dynamic stressstrain curves for rocks. Int J Rock Mech Min Sci 37(7): $1055-1060$

Li XB, Lok TS, Zhao J (2005) Dynamic characteristics of granite subjected to intermediate loading rate. Rock Mech Rock Eng 38(1):21-39

Li XB, Zhou ZL, Lok TS, Hong L, Yin TB (2008) Innovative testing technique of rock subjected to coupled static and dynamic loads. Int J Rock Mech Min Sci 45(5):739-748

Li XB, Zhou ZL, Liu DS, Zou Y, Yin TB (2011) Wave shaping by special shaped striker in SHPB tests. In: Zhou YX, Zhao J (eds) Advances in rock dynamics and applications. CRC Press, Boca Raton, p 105-123

Lok TS, Li XB, Liu DS, Zhao PJ (2002) Testing and response of large diameter brittle materials subjected to high strain rate. ASCE J Mater Civil Eng 14(3):262-269

Lu YB, Li QM, Ma GW (2010) Numerical investigation of the dynamic compressive strength of rocks based on split Hopkinson pressure bar tests. Int J Rock Mech Min Sci 47(5):829-838

Ma GW, Wang XJ, Li QM (2010) Modeling strain rate effect of heterogeneous materials using SPH method. Rock Mech Rock Eng 43:763-776

Ma GW, Wang XJ, Ren F (2011) Numerical simulation of compressive failure of heterogeneous rock-like materials using SPH method. Int J Rock Mech Min Sci 48(3):353-363

Park SW, Xia Q, Zhou M (2001) Dynamic behavior of concrete at high strain rates and pressures: II. Numerical simulation. Int J Impact Eng 25(9):887-910

Potyondy DO, Cundall PA (2004) A bonded-particle model for rock. Int J Rock Mech Min Sci 41(8):1329-1364

Qi CZ, Wang MY, Qian QH (2009) Strain-rate effects on the strength and fragmentation size of rocks. Int J Impact Eng 36(12): $1355-1364$

Ravichandran G, Subhash G (1994) Critical appraisal of limiting strain rates for compression testing of ceramics in a split Hopkinson pressure bar. J Am Ceram Soc 77(1):263-267

Read RS (2004) 20 years of excavation response studies at AECL's Underground Research Laboratory. Int J Rock Mech Min Sci 41(8):1251-1275

Tedesco JW, Ross CA (1998) Strain-rate-dependent constitutive equations for concrete. ASME J Press Vessel Technol 120(4): 398-405

Wang YN, Tonon F (2009) Modeling Lac du Bonnet granite using a discrete element model. Int J Rock Mech Min Sci 46(7):1124-1135

Xia K, Nasseri MHB, Mohanty B, Lu F, Chen R, Luo SN (2008) Effects of microstructures on dynamic compression of Barre granite. Int J Rock Mech Min Sci 45(6):879-887 
Zhang QB, Zhao J (2013a) A review of dynamic experimental techniques and mechanical behaviour of rock materials. Rock Mech Rock Eng. doi:10.1007/s00603-013-0463-y

Zhang QB, Zhao J (2013b) Determination of mechanical properties and full-field strain measurements of rock material under dynamic loads. Int J Rock Mech Min Sci 60:423-439

Zhang QB, Zhao J (2013c) Effect of loading rate on fracture toughness and failure micromechanisms in marble. Eng Fract Mech 102:288-309

Zhao J, Zhou YX, Hefny AM, Cai JG, Chen SG, Li HB, Liu JF, Jain M, Foo ST, Seah CC (1999) Rock dynamics research related to cavern development for ammunition storage. Tunn Undergr Sp Tech 14(4):513-526
Zhou ZL, Li XB, Ye ZY, Liu KW (2010) Obtaining constitutive relationship for rate-dependent rock in SHPB tests. Rock Mech Rock Eng 43(6):697-706

Zhou ZL, Li XB, Liu AH, Zou Y (2011) Stress uniformity of split Hopkinson pressure bar under half-sine wave loads. Int J Rock Mech Min Sci 48(4):697-701

Zhou YX, Xia K, Li XB, Li HB, Ma GW, Zhao J, Zhou ZL, Dai F (2012) Suggested methods for determining the dynamic strength parameters and mode-I fracture toughness of rock materials. Int J Rock Mech Min Sci 49:105-112

Zhu WC, Bai Y, Li XB, Niu LL (2012) Numerical simulation on rock failure under combined static and dynamic loading during SHPB tests. Int J Impact Eng 49:142-157 